"Parallel-stranded hairpins containing 8-aminopurines. Novel efficient probes for triple-helix formation.” Aviñó, A., Morales, J.C., Frieden, M., de la Torre, B.G., Güimil-García, R., Cubero, E., Luque, F.J., Orozco, M., Azorín, F., Eritja, R. Bioorg. Med. Chem. Lett., 11(13), 1761-1763 (2001). doi: 10.1016/S0960/S0960-894X(01)00295-5

\title{
Parallel-Stranded Hairpins Containing 8-Aminopurines. Novel Efficient probes for triple-helix formation.
}

\author{
Anna Aviñó ${ }^{\star}$, Juan Carlos Morales, Miriam Frieden ${ }^{\&}$, Beatriz G. de la Torre, Ramon Güimil García, \\ Elena Cubero ${ }^{\#}$, F. Javier Luque ${ }^{\#}$, Modesto Orozco ${ }^{\#}$, Ferran Azorín, Ramon Eritja* . \\ Instituto de Biología Molecular de Barcelona, C.S.I.C., Jordi Girona 18-26, E-08034 Barcelona, Spain. \\ ${ }^{\star}$ Cygene Spain S.L., Parc Científic de Barcelona, Baldiri i Reixac, 10-12. E-08028 Barcelona, Spain. \\ ${ }^{\#}$ Universitat de Barcelona. Martí i Franquès 1-11, E-08028 Barcelona, Spain.
}

\begin{abstract}
We describe novel oligomers with a greater propensity to form triplexes than oligomers containing only natural bases. They consist of a polypyrimidine sequence linked head-to-head with a polypurine sequence carrying one or several 8-aminoadenine or 8-aminoguanines. The presence of 8 aminopurines also stabilized the parallel-stranded duplex structure.
\end{abstract}

Oligonucleotides bind in a sequence-specific manner to homopurine-homopyrimidine nucleic acid sequences to form triple helices, or triplexes. ${ }^{1}$ This offers the possibility of designing DNA- and RNAbinding molecules, which may have applications. A large effort has therefore been devoted to the design and preparation of modified oligonucleotides in order to enhance triple helix binding stability. ${ }^{2}$

The synthesis of oligonucleotides containing 8-aminopurines has been described. ${ }^{3-7}$ The introduction of an amino group at position 8 of adenine and guanine increases the stability of the triple helix due to the combined effect of the gain of one Hoogsteen purine-pyrimidine H-bond (scheme 1), ${ }^{3,4,7}$ and the propensity of the amino group to be integrated into the "spine of hydration" located in the minor-Major groove of the triplex structure. ${ }^{3,7}$
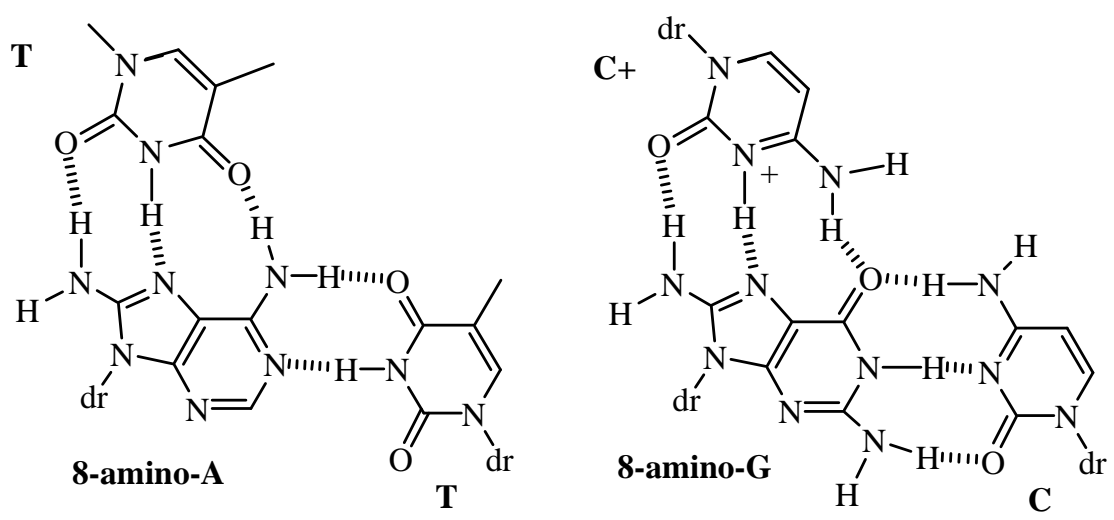
Scheme 1. Hypothetical base-pairing schemes of triads containing 8-aminopurines

Although the preparation and binding properties of oligonucleotides containing 8-aminopurines have been described, natural oligonucleotides containing 8-aminopurines cannot bind double-stranded DNA sequences because the modified bases are purines that are in the target sequence rather than in the Hoogsteen strand used for specific recognition. Here we describe the preparation and binding properties of oligonucleotides carrying 8-aminoadenine and 8-aminoguanine, connected head-to-head to the Hoogsteen pyrimidine strand. These modified oligonucleotides, which are a special class of parallel-stranded DNA, allow the specific recognition of single-stranded nucleic acids by binding to a polypyrimidine strand by triple helix formation.

Oligonucleotide sequences (R-22: ${ }^{5}$ GAA GGA GGA GA ${ }^{3}-(\mathrm{EG})_{6^{-}}{ }^{3}$ TCT CCT CCT TC ${ }^{5}$, R-22A: ${ }^{5}$ GAA GGA $^{\mathbf{N}}$ GGA $^{\mathbf{N}}$ GA $^{3}{ }^{\prime}-(\mathrm{EG})_{6^{-}}{ }^{3}$ TCT CCT CCT TC ${ }^{5}$, R-22G: ${ }^{5}$ GAA GG ${ }^{\mathbf{N}}$ A GG ${ }^{\mathbf{N}}$ A GA ${ }^{3}{ }^{\prime}-(\mathrm{EG})_{6^{-}}{ }^{3}$ TCT CCT CCT TC ${ }^{5}$ were $\mathbf{A}^{\mathbf{N}}, \mathbf{G}^{\mathbf{N}}$ and -(EG) 6 are 8-aminoadenine, 8-aminoguanine and hexaethyleneglycol) were prepared using phosphoramidite chemistry on an automatic DNA synthesizer. The parallel-stranded oligomers were prepared as follows. ${ }^{8,9}$ First, the pyrimidine part was assembled using reversed $\mathrm{C}$ and $\mathrm{T}$ phosphoramidites and a reversed C-support (a support that had the nucleoside linked through the 5' end). Then, a hexaethyleneglycol linker was added using a commercially available phosphoramidite. Finally, the purine part carrying the modified 8-aminopurines was assembled using standard phosphoramidites for the natural bases and the 8-aminopurine phosphoramidites. The phosphoramidites of 8-aminoadenine, 8aminoguanine and 8-aminohyoxanthine were prepared as described previously. ${ }^{3-7}$

The relative stability of triple helices formed by the parallel-stranded hairpins and the polypyrimidine target sequence (WC-11mer: ${ }^{5}$ 'TCT CCT CCT TC $^{3}$ ') was measured spectrophotometrically at different values of $\mathrm{pH}(\mathrm{pH} 4.6,6.0$ and 7.0). In all cases, one single transition was observed with hyperchromicity of around $25 \%$ at $\mathrm{pH} 4.6$ and $20 \%$ at $\mathrm{pH} 7$, which was assigned to the transition from a triplex to a random coil. Melting temperatures are shown in Table 1. Thermal renaturation was also studied by running a decreasingtemperature gradient. No differences were observed, indicating that strand association and dissociation is fast. Replacement of two adenines or two guanines by two 8-aminoadenines $\left(\mathrm{A}^{\mathrm{N}}\right)$ or two 8-aminoguanines $\left(\mathrm{G}^{\mathrm{N}}\right)$ stabilized triple helix, especially at $\mathrm{pH} 6$ and 7 where an increase in the melting temperature of $5-10^{\circ} \mathrm{C}$ per substitution was observed (Table 1). The presence of $\mathrm{G}^{\mathrm{N}}$ produced a higher stabilization than $\mathrm{A}^{\mathrm{N}}$ in agreement with previous results on different targets. ${ }^{3,7}$

Table 1. Melting temperatures ${ }^{\mathrm{a}}\left({ }^{\circ} \mathrm{C}\right)$ for the triplex formed by hairpin derivatives and their target. 


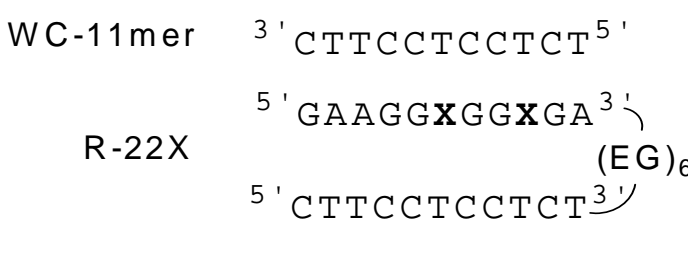

R-22A, X = 8-aminoadenine

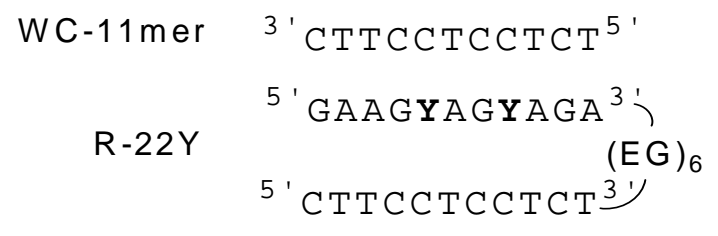

$R-22 G, Y=8$-aminoguanine

\begin{tabular}{|l|l|l|l|l|l|l|l|l|}
\hline Hairpin & Target & $\mathrm{pH} 4.6$ & $\Delta \mathrm{Tm}^{\mathrm{b}}$ & $\mathrm{pH} 6.0$ & $\Delta \mathrm{Tm}^{\mathrm{b}}$ & $\mathrm{pH}^{\mathrm{b}} .0$ & $\Delta \mathrm{Tm}^{\mathrm{b}}$ & Duplex $^{\mathrm{c}}$ \\
\hline R-22 & WC11mer & $\mathbf{6 9}$ & 0 & $\mathbf{4 7}$ & 0 & $\mathbf{3 2}$ & 0 & 51 \\
\hline R-22A & WC11mer & $\mathbf{7 3}$ & 4 & $\mathbf{5 6}$ & 9 & $\mathbf{4 5}$ & 13 & 41 \\
\hline R-22G & WC11mer & $\mathbf{7 6}$ & 7 & $\mathbf{5 9}$ & 12 & $\mathbf{5 1}$ & 19 & 38 \\
\hline R-22 & none & $\mathbf{4 6}$ & 0 & $\mathbf{2 5}$ & 0 & -- & -- & \\
\hline R-22A & none & $\mathbf{6 4}$ & 18 & $\mathbf{4 3}$ & 18 & -- & -- & \\
\hline R-22G & none & $\mathbf{6 8}$ & 22 & $\mathbf{5 0}$ & 25 & $\mathbf{3 9}$ & -- & \\
\hline
\end{tabular}

${ }^{\mathrm{a}} 1 \mathrm{M} \mathrm{NaCl}, 100 \mathrm{mM}$ sodium phosphate/ citric acid buffer

${ }^{\mathrm{b}} \Delta \mathrm{Tm}=\mathrm{Tm}-\mathrm{Tm}$ of $\mathrm{R}-22$ in the same conditions

'Control duplex [d(5'GAAGYXGYXGA3'.d(3'CTTCCTCCTCT5')) 1M NaCl, 100 mM sodium phosphate/ citric acid pH 6.0

In order to check that the transition was due to triple helix formation, melting curves were performed with hairpins (R-22, R-22A, R-22G) in the absence of the polypyrimidine target sequence (WC-11 mer). In this case, a single transition was also observed, but at lower temperature and with hyperchromicity around 10$15 \%$. This indicates that the transition observed with WC-11mer (triple helix) is different from the transition observed without WC-11mer (parallel-stranded double helix). The control duplex formed by WC-11mer (without the Hoogsteen part) melted at lower temperatures than triplexes (at $\mathrm{pH}$ 6.0) when 8-aminopurines were present (Table 1).

The transition observed in the absence of WC-11 mer indicates that R22 derivatives have a parallelstranded structure. This structure was more stable at $\mathrm{pH} 4.6$ and in the presence of 8 -aminopurines. Because one of the structures observed in parallel-stranded DNA is a Hoogsteen base pair ${ }^{14}$, which may be stabilized by the presence of 8-aminopurines, we believe that the Hoogsteen base pair is responsible for the stability of the parallel structure observed in R22 derivatives. Because the Hoogsteen base pair is very similar to the structure that it is expected to have in the triple helix (scheme 1) we believe that the hairpin derivatives described in this work have a "preformed" structure that may facilitate the formation of triple helices. In any case, the presence of 8 -aminopurines produced the highest stabilization of the parallel structure ever reported in natural oligonucleotides (between 9 and $12^{\circ} \mathrm{C}$ per substitution, Table 1) even higher than the stabilization observed in the triplex (Fig. 1).

Binding of hairpins to target was also analysed by gel-shift experiments. The target was labelled with $\left[\gamma-{ }^{32} \mathrm{P}\right]$-ATP and polynucleotide kinase and increasing amounts of the hairpins were added to solution of the labelled target. After incubation at room temperature for $30 \mathrm{~min}$, the mixtures were analysed by 
polyacrylamide gel electrophoresis (PAGE). The formation of the triplex was followed by the appearance of a major band with less mobility than the band corresponding to the target alone. This binding was specific because hairpins did not bind oligonucleotides without the target polypyrimidine sequence (data not shown).

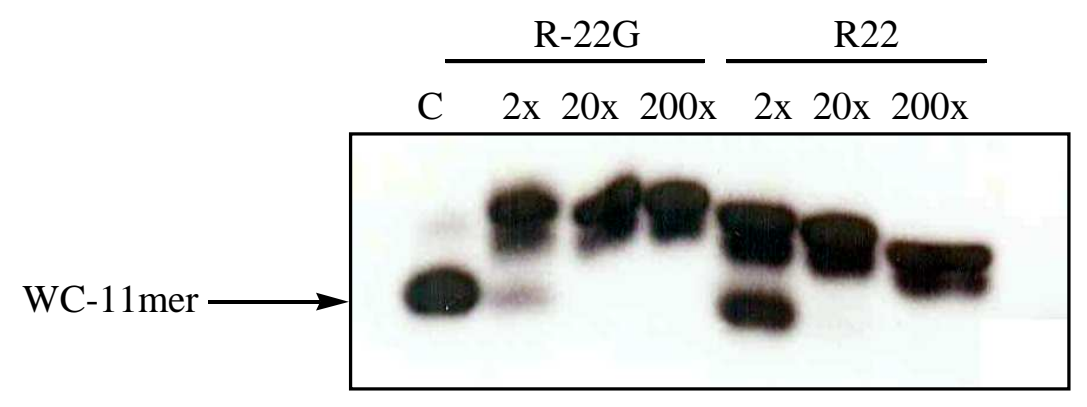

Figure 1: Binding of parallel-stranded hairpins to polypyrimidine target WC-11mer by gel shift experiments. ${ }^{32}$ P-labelled DNA target and the natural (R-22) or modified (R-22G) parallel stranded hairpins were separately annealed in a citric-phosphate buffer ( $\mathrm{pH} \mathrm{6)}$ of $100 \mathrm{mM} \mathrm{Na}+$. Binding was started by mixing $10 \mu \mathrm{L}$ of a solution containing the radiolabelled DNA target $(20 \mathrm{nM})$ and $10 \mu \mathrm{L}$ of a solution containing hairpin at different concentrations ( $40 \mathrm{nM}, 400 \mathrm{nM}$ and $4 \mu \mathrm{M}$ ). The resulting solution was incubated for 30 min at room temperature. Phytol loading buffer $(5 \mu \mathrm{L})$ was added to the solution and the mixture was analysed by running the samples on $15 \%$ native polyacrylamide gels at $4^{\circ} \mathrm{C}$.

Theoretical calculations on the stability of Hoogsteen and Watson-Crick pairing were performed using AMBER-99 force-field ${ }^{11}$ and the standard B-type geometry for triplex ${ }^{12}$. Results (Table 2) demonstrate the stabilization of parallel stranded duplexes and triplexes by the 8-amino group, while the Watson-Crick pairing was not modified. Thus, theoretical results agree with a Hoogsteen-pairing for the parallel stranded hairpins, as well as with the hypothesis that improved H-bonding is responsible for the 8-amino-induced stabilization of the parallel duplex.

We described the triplex stabilization properties of hairpins formed by a polypyrimidine part linked head-to-head with a polypurine sequence carrying several 8-aminopurines: 8-aminoadenines or 8aminoguanines. These modified hairpins bind specifically to a predetermined polypyrimidine target by forming stable triplex that can be observed even at $\mathrm{pH}$ 7. The high degree of stabilization obtained with the addition of several 8-aminopurines is especially relevant to the development of new applications based on triple helix formation such as structural studies, DNA-based diagnostic tools and antigene therapy.

Table 2. Energy values for the Watson-Crick and Hoogsteen interaction of adenine, guanine and their 8-amino derivatives and their complementary bases (thymine and cytosine).

\begin{tabular}{|l|l|l|}
\hline & WC & Hoogsteen $^{\text {a }}$ \\
\hline
\end{tabular}




\begin{tabular}{|c|c|c|}
\hline & (thymine/cytosine) & (thymine/cytosine) \\
\hline Adenine & -13.1 & -14.0 \\
\hline 8-Amino Adenine & -12.8 & -19.6 \\
\hline Guanine & -22.1 & -32.3 \\
\hline 8-Amino Guanine & -24.7 & -35.1 \\
\hline
\end{tabular}

${ }^{\mathrm{a}}$ For Hoogsteen pairs $\mathrm{G} \bullet \mathrm{C}$ and $8 \mathrm{AG} \bullet \mathrm{C}$ the cytosine is considered in its $\mathrm{N} 3-\mathrm{H}$ protonated form.

Acknowledgements. The authors thank the Dirección General de Investigación Científica y Técnica (projects PB98-1222, PM99-0046 and BQU2000-0649), the Generalitat de Catalunya (project 2000-SGR-0018) and CyGene, Inc. for financial support.

\section{REFERENCES AND NOTES}

1. Thuong, N.T., Hélène, C. Angew.Chem. Int. Ed. Engl., 1993, 32, 666.

2. Soyfer, V.N., Potaman, V.N. Triple helical Nucleic Acids 1996 Springer-Verlag, New York.

3. Güimil García, R., Ferrer, E., Macías, M.J., Eritja, R., Orozco, M. Nucleic Acids Res., 1999, 27, 1991.

4. Kawai, K., Saito, I., Sugiyama, H. Tetrahedron Lett. 1998, 39, 5221.

5. Rao, T.S., Durland, R.H., Revankar, G.R. J. Heterocyclic Chem., 1994, 31 , 935.

6. Rieger, R.A., Iden, C.R., Gonikberg, E., Johnson, F. Nucleosides Nucleotides, 1999, 18, 73.

7. Soliva, R., Güimil-García, R. Blas, J.R., Eritja, R., Asensio, J.L., González, C., Luque, F.J., Orozco, M. Nucleic Acids Res., 2000, 28,4531 .

8. Kandimalla, E.R., Agrawal, S. Biochemistry 1996, 35, 15332.

9. Rippe, K., Jovin, T.M. Methods in Enzymology 1992, 211, 199.

10. Germann, M.W., Zhou, N., van de Sande, J.H., Vogel, H.J., Methods in Enzymology 1995, $261,207$.

11. Cheatham,T.E.; Cieplak,P.; Kollman,P.A. Journal of Biomolecular Structure \& Dynamics, 1999, $16,845$.

12. Soliva,R.; Laughton,C.A.; Luque,F.J.; Orozco,M. J.Am.Chem.Soc., 1998, 120, 11226. 